\title{
TRAVESTILIDADE COMO DENÚNCIA POLÍTICA: PERFORMATIVIDADE DE GÊNERO E PANANTILLANISMO EM SIRENA SELENA VESTIDA DE PENA
}

\section{TRAVESTILITY AS POLITICAL DENUNCIATION: GENDER PERFORMATIVITY AND PANANTILLANISMO IN SIRENA SELENA VESTIDA DE PENA}

\author{
BAROSSI, Luana \\ MARCELO, Thais Neves
}

\begin{abstract}
RESUMO: Este breve ensaio propõe uma leitura do romance Sirena Selena vestida de pena levando em consideração sua matéria política, encontrada no tema da travestilidade. Dessa maneira, serão abordadas duas possibilidades interpretativas sobre o caráter subversivo da narrativa: a diversidade de gênero, que desestabiliza a tradição patriarcal, heterossexista e cissexista da sociedade caribenha e a travestilidade como alegoria do Caribe, cujo foco está na denúncia de problemáticas econômicas e sociais.
\end{abstract}

PALAVRAS-CHAVE: Travestilidade, estudos de gênero, literatura caribenha.

\begin{abstract}
This brief essay aims to analyze the novel Sirena Selena vestida de pena taking into consideration its political matter, found in the topic of travestility. We will approach two different interpretative possibilities about the subversive matter of the narrative: firstly, gender diversity, that destabilizes the patriarchal, heterosexist and cissexist Caribbean society tradition, and secondly, travestility as an allegory of the Caribbean, which focus on the denunciation of economic and social matters.
\end{abstract}

KEYWORDS: Travestility, gender studies, caribbean literature. 


\section{1 jangada}

Sirena Selena vestida de pena é um romance de Mayra Santos-Febres publicado pela primeira vez em 2000. O narrador, por vezes heterodiegético, por vezes autodiegético, assumindo a perspectiva de diferentes personagens, constrói a história por meio da junção das memórias das personagens. Assim, a obra não assume uma linearidade temporal, mas é construída no processo de leitura conforme as diferentes memórias se sobrepõem, trazendo as especificidades de cada personagem. Mesmo as personagens descritas, em um primeiro momento, como más (por uma leitura maniqueísta e apressada), têm suas memórias construídas na narrativa em outros momentos, fazendo com que sejam compreendidos os elementos que as compõem, de maneira a trazer ao leitor informações que permitem relativizar determinadas atitudes ou ao menos apreender as razões ou impulsos que fizeram a personagem agir dessa maneira.

A personagem que dá nome à narrativa, Sirena, às vezes é tratada no masculino, às vezes no feminino. Um garotinho drogado catando latas nas esquinas de Porto Rico é encontrado pelas drag queens (ou dragas) que se apresentavam no bar Danúbio Azul. O garoto cantava boleros tristes com uma voz impressionantemente bela, como um "ángel dominical" (p. 11), o que chamou a atenção das dragas. Elas chamam sua empresária, Martha Divine, que passa a agir como mãe e agente do menino. Mais à frente na narrativa, o tempo retorna ao momento anterior a esse, quando Sirenito vivencia a morte de sua primeira "mãe" de rua, Valentina Frenesí. Martha Divine passa a agenciar Sirenito, ajudando-o a se transformar em uma belíssima draga. Como tinha apenas quinze anos e o trabalho infantil era proibido em Porto Rico, Divine viaja com Sirena para a República Dominicana, para agenciar seu show em hotéis de luxo:

— Ni mintiendo te lo dan, mi amor, que las leyes federales prohíben el child labour. ¿Tú no sabías eso? Así que mejor — le dijo su mamá-, mejor nos vamos a la República Dominicana que allí no se tragan esos cuentos.

Y ahora, gracias a las leyes federales, Sirena Selena estaba a punto de convertirse en la diva del Caribe. Despertaría ansias en todo un público nuevo, con la ilusión de su canto. (SANTOS-FEBRES, 2011, p. 12)

Desta maneira, o Caribe se delineia geograficamente e politicamente no decorrer da narrativa, que expõe as semelhanças e diferenças entre as ilhas, as contradições e a vida de pessoas que habitam o "lado de fora" dos empreendimentos turísticos, apesar de trabalharem nas suas dependências. Como afirma a socióloga caribenha Kamala Kempadoo, 
Sexual-economic exchanges appear as crucial for the sustenance of the region in the face of inequalities that global capitalism has created in the small Caribbean nations and territories. This sexual economy is furthermore deeply embedded in industries that are tightly integrated into the global economy, such as tourism and mining. Race and ethnicity factor intricately into this farreaching sexual economy, and (...) these factors shape ideals and fantasies about the exotic, engendering sexual labor migrations and sex tourism. (KEMPADOO, 2004, p. 3)

Logo, apesar do espaço da narrativa se restringir aos países da chamada Grande Antilha, mais especificamente Porto Rico e República Dominicana, o enredo traz discussões sobre raça, turismo sexual e gênero, pertinentes para todo o território caribenho. Ademais, é importante para tal análise pensar as condições sociopolíticas desses países, uma vez que suas posições dentro do panorama do mercado mundial influenciam diretamente na maneira como os corpos caribenhos são lidos e explorados. Portanto, não apenas a condição de países em desenvolvimento (ou "terceiromundistas") é importante, mas também como alguns desses territórios não possuem total autonomia política, como é o caso de Porto Rico, cujo status é de Estado livre associado aos Estado Unidos.

A temática da subversão política está fortemente relacionada a toda a obra de Mayra Santos-Febres, uma vez que seus protagonistas, assim como a própria autora ${ }^{1}$, são personagens que transitam por espaços alheios aos dispositivos de poder (Foucault, 1979), delineados pelos valores neocoloniais e sexistas da sociedade caribenha. Ao ganharem protagonismo, essas personagens burlam as esferas disciplinantes, gerando novas demandas simbólicas e culturais.

Em seu ensaio La narrativa de Mayra Santos y el travestismo cultural, Luis Felipe Díaz propõe um embate entre Mayra Santos-Febres e a tradição literária porto-riquenha dos anos 1970. Segundo o autor, a escritora confronta essa tradição que, mesmo criticando as estruturas imperialistas e colonizadoras, não questiona os valores patriarcais e falocêntricos dessa sociedade.

\footnotetext{
${ }^{1}$ Mayra Santos-Febres, em Literatura para cura el asma: una entrevista con Mayra Santos-Febres, por Marcia Morgado, afirma: "Soy mujer, negra, caribeña y quién sabe qué otras cosas más que me colocan en un margen". Nesse momento, além de se assumir como um corpo marginalizado, afirma que as marginalidades são categorias móveis, o que interfere na maneira como aborda esses temas em sua obra: "Precisamente por esa movilidad me doy permiso para transitar por varios mundos, por varios márgenes, a veces hasta por el centro. Y así me conecto con la gente que, como yo, anda visitando por ahí, transgrediendo fronteras sociales."
} 
De ahí que Mayra Santos reconozca que los actos corporales reprimidos, en cuanto perversos y transgresores, adquieren dimensiones significativas, no sólo por ofrecer oposición a las domesticaciones y vigilancias del poder domesticador, sino por abrirles nuevos caminos a los centrípetos y nómadas deseos que expresan un mundo muy diferente que ya tenemos encima y que amenaza (y algunos postmodernos dirían que transforma radicalmente) más que nunca, nuestra identidad (DÍAZ, 2003, p. 31).

Desta forma, é possível pensar no romance como uma transgressão a partir dos personagens cujos corpos não estão inseridos dentro de um estereótipo binário de gênero. Sirena Selena Vestida de Pena tem as dragas ${ }^{2}$, corpos classificados como masculinos pela estrutura social binária de gênero, travestidos de elementos socialmente relacionados a uma feminilidade exagerada, como é o caso de Martha Divine:

Martha, toda una señora[...]. Era alta y rubia oxigenada, ya con sus arrugas, con su par portentoso de pechos de silicón con piel increíblemente tersa por las hendiduras del escote. Bronceada y de piernas largas, siempre llevaba las uñas esmaltadas de rojo granate, todo un coágulo de sangre en la punta de cada uno de sus dedos, los de los pies, los de las manos. No exhibía un solo pelo que la delatara. Solo su altura y su voz y sus ademanes tan femeninos, demasiado femeninos, estudiadamente femeninos. (SANTOS-FEBRES, 211, p. 9)

A obra apresenta também corpos vistos como andróginos, como os de Leocadio, de Sirena quando não está "montada", de Hugo Graubel em sua infância e de Luisito Cristal: “Cogió valor y empezó a probarse ropa más andrógina, más atrevida, hasta que, un buen día, llegó al Flying Saucer, vestido con una minifalda plateada que le prestó su noviecita” (p. 29). Logo, o gênero, na narrativa, está associado com as concepções desenvolvidas por Judith Butler e Rosi Braidotti, pois se trata de uma categoria performática, e, portanto, móvel, com o poder de ir contra as categorias normativas do binarismo (no qual os gêneros feminino e masculino

\footnotetext{
2 "Dragas" é a maneira como as drag queens boricuas (porto-riquenhas) se autodesignam.
} 


\section{jangada}

estão determinados por estereótipos rígidos e relacionados a fatores biológicos) e se apresentam muitas vezes de maneira fluida, em constante devir.

Esta proposição de gênero não se afasta da especificidade da localização geopolítica, mas intensifica a crítica à sua construção histórica por meio da violência colonial. Braidotti (2002) reforça que essas ideias são inseparáveis da noção de responsabilidade epistemológica e política, pensada como aquela prática que consiste em desvelar as relações de poder que habitam inclusive na própria noção de identidade. A desconstrução dessas relações de poder instituídas socialmente implica na responsabilidade de perceber que elas provocam uma relação entre corpos (nos termos de Spinoza) e na ação de desfazer as diferenças de poder por meio de uma montagem ou relação entre memória e narrativas, que, por sua vez, são capazes de converter em representação simbólica o que escapa à consciência.

Judith Butler, em seu livro Problemas de gênero: feminismo e subversão da identidade, desenvolve o conceito de devir para denominar as performatividades que transitam de um estereótipo de gênero ao outro, como a travestilidade, e que, assim, confrontam as categorias tradicionais de gênero:

Por mais que crie uma imagem unificada da 'mulher' (...), o travesti (sic) também revela a distinção dos aspectos da experiência do gênero que são falsamente naturalizados como uma unidade através da ficção reguladora da coerência heterossexual. Ao imitar o gênero, a drag revela implicitamente a estrutura imitativa do próprio gênero - assim como sua contingência. Aliás, parte do prazer, da vertigem da performance, está no reconhecimento da contingência radical da relação entre sexo e gênero diante das configurações culturais de unidades causais que normalmente são supostas naturais e necessárias. No lugar da lei da coerência heterossexual, vemos o sexo e o gênero desnaturalizados por meio de uma performance que confessa sua distinção e dramatiza o mecanismo cultural de sua unidade fabricada. (BUTLER, 2015, p. 237)

Ademais, como afirma Alejandra López Guevara, em sua tese Travestismo y humor en Sirena Selena vestida de pena, de Mayra Santos-Febres. Apuntes desde el carnaval bajtiniano, este gênero, em constante mudança, concordando com o devir do momento de cada personagem, é marcado pelo narrador com a alternância de artigos femininos e masculinos, ao se referir à Sirena. A essa marca estilística, López Guevera atribui a denominação de 
travestismo lingüístico (p. 104): “pero bien sabía la sirena que para él no había gran diferencia entre un hogar de crianza y un círculo en el infierno" (SANTOS-FEBRES, 2011, p. 10).

Além do travestismo linguístico ${ }^{3}$, é possível identificar um hibridismo literário que acompanha a performatividade de cada personagem, transformando-as, por vezes, no narrador. O texto é majoritariamente narrado em terceira pessoa, por um narrador heterodiegético e onisciente, porém, há momentos em que o narrador se converte em autodiegético, como, por exemplo, nas memórias de Martha Divine:

Yo la conozco desde hace tiempo, de cuando hacía shows en el Flying Saucer, trepada en las tarimas para go-go dancers, vestida con leotardos plateados, capas de plástico traslúcido y botas recubiertas de cristal. Un escándalo la Luisito. En esa discoteca fue la primera vez que la conocimos las chicas del ambiente. Era para la época en que yo me estrenaba como Miss Martha Divine. (SANTOS-FEBRES, 2011, p. 29)

Ou ainda nas apresentações de Martha no Danúbio Azul:

Bienvenido, estimado público, ¿cómo están ustedes? ¿Todo bien, todo fabulous, todo too much? Pues les quiero dar la bienvenida a mi show, a nombre mío y a nombre de toda la administración de la discoteca Boccaccio's, este antro de perdición para locas locales e internacionales, turistas y nativas, y para indecisos y chicos open minded, buchas, y mujeres biológicas que lo que les gusta es sentarse a mirar hombres grajeándose... las pooobres. (SANTOS-FEBRES, 2011, p. 113)

Além de se apresentar como heterodiegético e autodiegético, o narrador às vezes desaparece, configurando momentos dramáticos, nos quais há apenas diálogos entre as personagens, como nas memórias de criança de Sirena, quando trabalhava nas casas de ricos com sua avó:

A ver, ¿Dónde habré dejado yo las llaves de la casa esta? Bolsillo, cartera, bolsillo de la bata. Aquí están, Abuela. ¿No te acuerdas que me las diste a mí

\footnotetext{
${ }^{3} \mathrm{O}$ termo "travestismo" foi mantido por se tratar de um conceito apropriado da tese de Alejandra Lopéz Guevara. Porém, o uso preferido neste trabalho é "travestilidade", entendendo a carga pejorativa atribuida pelo sufixo "ismo" à palavra.
} 
para que no se te perdieran? Ay sí, mijito, es que tengo la cabeza loca. Ponerse viejo es lo peor del mundo. ¿Y la luz? Vamos a abrir las ventanas que esto está como guarida de oso. Esta gente vive más encerrá que los cangrejos. Es que tienen aire central, Abuela. ¿Cómo que aire central, si el aire corre por todas partes? No, abuela, aire acondicionado en toda la casa. Lo que pagarán de electricidad. Más de lo que les cobro yo por limpiarles este cagadero. Parece que aquí hubo fi esta. Mira como está la colilla de cigarrillo y las botellas por todas partes. ¿Y ese polvo? Abuela, yo creo que eso es cocaína ¡Qué va a ser, muchacho, si esta gente es decentísima, abogados los dos! El que sean abogados no tiene que ver nada con que de vez en cuando se den su pasecito. (SANTOS-FEBRES, 2011, p. 37)

Por fim, há, além da travestilidade nas performances de gênero das personagens e, portanto, também nos aspectos formais do texto, a travestilidade alegórica das condições econômicas e sociais do Caribe, regidas por uma espécie de intra-colonialismo epistêmico. Intra-colonialismo epistêmico corresponde à repetição de atitudes, métodos e perspectivas colonialistas em uma dimensão micropolítica - como denunciou Gayatri Spivak ao questionar a univocidade da leitura sobre a subalternidade feita por alguns intelectuais -, que prevê uma perspectiva binária entre opressor/oprimido, e oblitera o lócus de enunciação de grupos dentro de um contexto de subalternidade (no caso específico de Spivak, a mulher na sociedade indiana), e apaga outras possibilidades de entender ou escrever a história.

No caso específico de Sirena Selena vestida de pena, o lócus de enunciação obliterado corresponde ao das dragas e demais personagens que transitam pelos espaços externos aos dispositivos de poder do espaço caribenho. Apesar desses espaços serem, por lado, negados às personagens, elas transitam também por eles, mas como mercadorias do turismo sexual. Há, no entanto, no decorrer do romance, diversas elucubrações nas montagens das memórias das personagens que permitem uma apropriação desses mesmos dispositivos como meio de sobrevivência, por um lado, mas de denúncia política, por outro.

A interpretação alegórica da obra é sugerida pela própria autora, quando, em entrevista, afirma:

...utilizo al personaje de Sirena..., un travestí [sic], de dos maneras, una metafórica y otra social. El concepto de travestismo me ayuda a pensar en cómo está organizada la sociedad en el Caribe y en América Latina: sus Jangada | nr. 9, jan/jun, 2017 | ISSN 2317-4722 - 22 | Pá g i n a 


\section{critica | literatura | artes \\ jangoada}

ciudades son travestís que se visten de Primer Mundo, adoptan los usos y las maneras que no les corresponden a fin de "escapar" de su realidad y acercarse a lo que cada día se ve más lejos: el progreso y la civilización. (SANTOSFEBRES citada por BARRADAS, 2003, pp. 57-58).

Barradas corrobora a leitura de Santos-febres em seu artigo, fazendo uma leitura dos parques temáticos caribenhos como se esses fossem "travestis" do "primeiro mundo". Ou seja, se fizermos uma sobreposição da representação alegórica feita pelo autor, o Caribe seria o gênero designado ao nascer e os parques temáticos criados para o desfrute especialmente dos norte-americanos seria representativo da travestilidade, como se aquele espaço se travestisse de "primeiro mundo". Discutiremos a posição de Barradas mais tarde neste artigo.

Contudo, a entrevista de Santos-Febres e o artigo de Barradas partem de uma perspectiva que coloca a travestilidade como uma representação negativa, no sentido de que serviria de alegoria política como um escape da realidade do "terceiro mundo". A travestilidade, nesse sentido, representaria uma espécie de fantasia alegórica de um desejo de repetir os pressupostos do intra-colonialismo epistêmico. Propomos, neste artigo, uma inversão desta noção. Nós argumentamos que a travestilidade é antes uma desterritorialização dos pressupostos colonialistas e sexistas que continuam a reger os dispositivos de poder dos espaços turísticos caribenhos, formando, então, uma alegoria política quase inversa à proposta por Efraín Barradas: a criação, por parte dessas personagens, de novas maneiras de existir, mesmo que para isso tenham que se apropriar dos mesmos dispositivos que as territorializavam para subverter seus mecanismos. Um exemplo disso no texto é a contratação de Sirena por Graubel para se apresentar em uma festa de alta sociedade onde sua presença seria normalmente rechaçada em decorrência de seu corpo não-normativo. Solange, a esposa de Hugo, representa essa perspectiva hegemônica:

— Carajo, Hugo, ¿cómo se te ocurre traer un travesti a la casa?

— ¡Y vuelve la burra al trigo! Solange, ya te expliqué mil veces que contraté a Sirena para que cantara unas canciones. ¿Cúal es el problema?

— ¿Cómo que cuál es el problema? Que trajiste a un aberrado a la casa. Lo metiste aquí sin consultarme. Y déjame felicitarte por el detallito de la cena. Te quedó bellísimo. Obligarme a mí a compartir mesa con esa porquería. (SANTOS-FEBRES, 2011, p. 163). 
Mas Solange compreende que o que provoca tal intranquilidade é outra questão: reside no ciúme e na possibilidade de perder o marido para Sirena: "Ese monstruo, ese maldito monstruo, ni por un instante puede acercarse a Hugo. De solo pensarlo, el alma de Solange se le resbala del pecho. Ella se la agarra con las manos. Necesita a Hugo para mantenerse en su sitial" (p. 173).

Sirena consegue subverter a relação de poder instituída e provocar, com seu canto de sereia, uma potência sedutora que desestabiliza a construção social vigente que a alocava, até então, no espaço da marginalidade. Até Solange, que tratava Sirena como um monstro, se deixa atravessar pela beleza do canto:

La Sirena es un ángel del demonio. Su voz sigue colándose por debajo de la puerta. Solange no quiere, pero escucha. Oye cómo canta el engendro, oye cómo abre las comisuras de la boca, oye distintamente cómo sale, nota a nota, aquella voz. Pelea, se tapa los oídos, se agarra el pecho; no quiere embelesarse con su voz. Se le cierran los ojos y ve cómo pasa su lengua por el labio para humedecerlo la Sirena, cómo traga saliva para limpiarse la garganta la Sirena, como coge aire para llenarse el pecho una vez más. Trata de no embelesarse, pero ya es tarde. La voz de la Sirena la coge en sus brazos ardientes con besos de muerte y la lleva hasta el mismísimo abismo de la soledad. Este monstruo es peligroso. No es de este mundo, su voz. [...] El aire, el aire se escapaba. La esposa de un banquero se sintió elevada por lo etéreo, agarró a su marido del brazo; quiso murmurar que no la dejara salir así, volando por sobre las cabezas de todos aquellos invitados tan ilustres, por sobre la cabellera negra de aquel travesti adolescente. la pura encarnación de lo imposible. (SANTOSFEBRES, 2011, pp. 173, 211-212)

Esse movimento de subversão, no entanto, é intercalado, na narrativa, pela denúncia do lugar subalterno daqueles indivíduos que sofrem discriminação econômica, sexual, racial e de gênero no Caribe, o que é possível afirmar a partir da trajetória de vida das personagens dragas, principalmente de Sirena. Elas, por não corresponderem às demandas normativas da sociedade, estão ainda mais marginalizadas, principalmente no âmbito econômico, o que explica a prostituição como, em determinados momentos de suas trajetórias, a única alternativa de sobrevivência. Neste ambiente da rua, vivem em constante ameaça, sujeitas a estupros e outras formas de violência física, como ocorre com o jovem Sirenito quando trabalhava nas ruas de 
Porto Rico com Valentina, sua primeira "mãe", que, preocupada com o paradeiro do menino, o encontra no instante seguinte ao estupro: "allí lo vio, con el pantalón a media pierna, con las manos encrespadas, con el calzoncillo ensangrentado..." (SANTOS-FEBRES, 2011, p. 88).

Além da violência física, as dragas sofrem violências simbólicas, referentes à falta de legitimidade frente o reconhecimento social de seus corpos, como é possível observar no momento em que o narrador afirma o nervosismo que Martha Divine sentia frente ao medo de que seu corpo não fosse reconhecido como feminino:

Poco a poco, los pasajeros fueron formando fi la para bajarse del avión. Miss Martha esperó a que Sirena sacara su neceser del compartimiento superior, cotejó que no se les quedara ningún bolso olvidado y buscó su lugar entre todos aquellos turistas, vendedores y familias que la acompañaban en la travesía. Empezó a sentir miradas sobre su cuerpo y el de su ahijada. "Ay, Jehovah, Dios de los ejércitos, dame valor. Esto es lo que más odio de los aterrizajes." Por más que trató de tranquilizarse, de nuevo a Martha, el ansia se le volvió un tumor vivo en el estómago. Comenzaron de nuevo las dudas. ¿Y si le notaban algo raro por las esquinas del maquillaje, y si a ella le pasaba lo que a la Maxine, que la leyeron tan pronto se bajó del 747, y le hicieron pasar vergüenza tras vergüenza en las oficinas de aduana? (SANTOSFEBRES, 2011, p. 22)

Neste momento e ao longo do romance é possível observar o grande desejo de Martha de fazer a cirurgia de redesignação sexual. Com isso, Martha, diferentemente de Sirena, se aproxima à identidade de uma mulher transexual, uma vez que, para ela, o trânsito entre feminino e masculino, assim como a acumulação de referentes simbólicos dos dois gêneros, não é desejada.

Outra violência simbólica sofrida pelas personagens diz respeito à privação de relações afetivas, sendo isso mais um fruto da falta de reconhecimento dos seus corpos, como ocorre com a personagem Margot, quando é abandonada pelo policial que havia se apaixonado por ela, suscitando o conselho de Martha à Sirena: “Ay nena, tú reza por no enamorarte jamás. (...) Es malo el amor en esta vida. Para cualquiera es malo, pero para una loca, es la muerte" (SANTOSFEBRES, 2011, p. 140).

Essas violências físicas e simbólicas também estão dirigidas aos corpos de aparência andrógina, como o de Sirenito, que além de ser homossexual com uma aparência frágil e 
delicada, é pobre e negro ${ }^{4}$. Frente a isso, ao abordar esse tema, Santos-Febres denuncia a condição da comunidade LGBT nos países "em desenvolvimento", em especial nos que têm o turismo como fonte importante de renda, pois os corpos diferentes daqueles que seguem um padrão hegemônico são vistos como objetos de consumo e não como agentes no contexto do turismo sexual, como afirma Teresa Peña-Jordan (2005, p. 275). A maneira como os homens viam Leocádio, Sirenito e Hugo Graubel e os violentavam, demonstra uma relação abusiva, na qual a violência parte de um corpo masculinizado e é dirigida a um corpo frágil dotado de traços considerados femininos pela estrutura cultural hegemônica.

Entretanto, é importante ressaltar a mudança particular que ocorre com a personagem de Hugo Graubel, que após ter sofrido essa violência física e simbólica durante a infância, passa a uma posição de agente nesse lugar de poder. Inserido na lógica colonizatória das relações de poder, Graubel, como um grande empresário, "controla, administra y se lucra de los recursos naturales y humanos del país caribeño" (SANTOS-FEBRES, 2011, p. 283). Para além disso, as relações sexuais e afetivas de Hugo estão marcadas por uma clara relação de dominância, na qual suas parceiras são destinadas a lugares de subalternidade, o que é exemplificado pela relação de que estabelece em seus relacionamentos com Solange e Sirena, com quem passa a se relacionar quando elas eram muito jovens. Ambas tinham cerca de quinze anos quando Hugo as aborda e, no caso de Solange, a pedofilia está ainda mais evidente, uma vez que seu marido já não a queria quando ela se transforma em uma mulher, o que o excitava era a porção infantil de Solange, a "cosa rara con leche entre las piernas y un marido como un perro eñangotado: lamiendo, lamiendo; aquella ambigüedad de pelos y caderitas niñas y pezoncitos en flor" (SANTOS-FEBRES, 2011, p. 165).

A partir disso se evidencia a denúncia que Santos-Febres tece em relação às novas formas de colonização e ao intra-colonialismo epistêmico, que partem do campo econômico e interferem na disposição de determinados corpos, ao estigmatizá-los e normatizá-los. Pois a inversão dos papéis dentro de uma dinâmica de poder com o personagem de Graubel só é possível diante de sua posição de homem normativo, branco e rico, diferentemente de Solange e Sirena.

\footnotetext{
${ }^{4} \mathrm{O}$ termo negro foi empregado neste artigo no lugar da palavra "mulato", pela conotação pejorativa desta e sua relação com o debate atual sobre colorismo. O Caribe, assim como a América Latina, apresenta fortes heranças da pigmentocracia, conceito desenvolvido pelo filósofo chileno Alejandro Lipschutz, que explica a maneira como a gradação da pigmentação da cor da pele de uma pessoa estabelece seu lugar em uma sociedade racialmente hierarquizada. Tal sistema, hoje, ao mesmo tempo em que "embranquece" negros de pele mais clara, como é o caso de Sirena ("la piel color canela clara" - SANTOS-FEBRES, 2011, p. 57), fazendo-os preferir os traços que se aproximam de um ideal branco; não os exclui da lógica racista dessas sociedades, marginalizando-os, portanto.
} 
Efraín Barradas em seu ensaio "Sirena Selena vestida de pena o el Caribe como travestî’, afirma que essas dinâmicas de poder nas esferas econômicas, sociais e sexuais nos países caribenhos estão fortemente ligadas à prostituição (tema constantemente abordado na narrativa de Sirena Selena vestida de pena). O turismo insere novas dinâmicas sexuais na população, principalmente naqueles mais marginalizados, como as dragas, sustentando-se, muitas vezes, a partir de práticas ilegais como a venda de corpos.

Dessa mesma maneira, pensando na relação entre travestilidade, turismo e prostituição, o autor sugere uma alegoria dos países caribenhos como travestis:

En términos generales el turismo impone sobre los países que dependen de esta industria una forma de travestismo. Nuestras ciudades o partes de ellas se transforman en theme parks, en parques temáticos para los visitantes que llegan en busca de una "otredad", de un mundo exótico, folclórico, de un mundo que muchas veces nada tiene que ver con la realidad cotidiana de los habitantes del país. El turismo, en ese sentido, nos impone un travestismo; nos obliga a transformarnos, para consumo del turista, en lo que no somos o no queremos ser permanentemente. (BARRADAS, 2003, p. 59)

O que propõe mais adiante em seu texto é um travestismo econômico, o qual é imposto aos países de "terceiro mundo" (sic) que dependem do turismo para sobreviver. Neste sentido, é possível pensar essa crítica presente no romance de Mayra Santos-Febres como uma reflexão que extrapola as fronteiras de seu país. No entanto, como já esboçado anteriormente neste artigo, consideramos que utilizar a travestilidade como alegoria deste "travestismo" dos países caribenhos para consumo dos turistas como denunciado por barradas é alocar a travestilidade e os corpos não-normativos em uma posição ainda mais marginal. Parece-nos que, apesar de traçar um questionamento político importante, Barradas não chega a questionar essa marginalização dos corpos não-normativos, na medida em que não procura ter um olhar cuidadoso sobre a questão, ao não diferenciar, em seu texto, a homossexualidade, a transgeneridade e a travestilidade: "la novela es mucho más que la recreación de las aventuras picarescas de unos homosexuales boricuas en la República Dominicana; la novela tiene una clara finalidad política" (BARRADAS, 2007, p. 58, grifo nosso).

Desta forma, ao aproximar, por meio de uma leitura alegórica, as dragas e demais personagens a uma estrutura de poder neocolonialista, está equiparando-as à posição de 
opressoras, o que, no nosso ponto de vista, corresponde a propagar as mesmas violências simbólicas que o autor procura criticar. O problema na leitura alegórica que o autor faz não é propriamente a denúncia política, no que concordamos com ele, mas a transposição representativa das dragas a esse cenário, como se a travestilidade fosse uma força representativa do poder neoimperialista. Ademais, a falta de cuidado com o tratamento à diversidade de gênero e orientação sexual expõe a negatividade da posição do autor com relação a esta questão.

Em contrapartida à proposta de Barradas, propomos, nesse artigo, que a travestilidade na obra é sim uma denúncia política, mas de outra natureza, em alguns aspectos até inversa à proposta pelo autor. As personagens da narrativa são apresentadas com todos seus questionamentos, dificuldades, fragilidades e traumas, mas na sobreposição temporal proporcionada pela leitura de cada capítulo, evidencia-se também sua força e sua potência transgressora às próprias construções do histórico colonial das ilhas e ao tal "travestismo" turístico denunciado por Barradas. Além de encontrarem na não-normatividade de seus corpos um meio de sobrevivência pelos shows, apresentações e, por vezes, prostituição, as personagens dragas encontram na travestilidade um meio de desterritorializar-se das construções sociais vigentes, mesmo essas que as enxergam como objetos de exotismo para o consumo de turistas estrangeiros.

No caso específico de Sirena, a travestilidade não se limita à transformação corporal em draga, mas na incorporação completa da figura da sereia. O canto da sereia seduz os que o escutam, mas também funciona como um mecanismo de autopreservação. Quando ainda trabalhava nas ruas com Valentina Frenesí, a personagem de Sirena se forma a partir da figura do pequeno Sirenito, quando relembra os boleros da avó e começa a cantar como um modo de suportar a vida da prostituição, criando um mecanismo de autopreservação, que também se constrói paulatinamente, primeiro em murmúrios, depois como um canto profundo:

Una noche, mientras un señor muy circunspecto le chupaba entre las piernas, el sireno empericado recordó un bolero entero de la abuela. Anteriormente, cuando la asaltaba la melancolía, tarareaba tonadas, cantaba pedacitos de coro, pero el bolero como tal se le escapaba, como si sufriera de un maleficio que le hacía olvidar las letras tan pronto le saltaba la entonación a la memoria. [...] Cantó, primero en murmullos, con los ojos cerrados, luego más pendiente al grano de su voz. El cliente paró su faena por un momento, pero luego, siguió chupando alelado con la canción del adolescente. Sirena seguía entonando 


\section{jangada}

boleros, uno tras otro. [...] Sin mirarle durante todo el trayecto de regreso, cogió el dinero en paga por sus servicios y se bajó del carro. Ni siquiera contó los billetes para asegurarse que el pago estaba completo. Todos los boleros de la abuela eran el caudal que necesitaba para protegerse para siempre de las noches en la calle (SANTOS-FEBRES, 2011, pp. 93-95).

No começo, era Sirenito, ao final, já era Sirena. Teresa Peña-Jordán, em seu ensaio “ $E l$ travestismo como estrategia de supervivencia en el Caribe: una lectura de Sirena Selena vestida de pena de Mayra Santos-Febres", propõe a travestilidade como uma ferramenta que garante a sobrevivência frente aos processos de marginalização. Dessa maneira, afirma a importância da performance para a personagem de Sirena:

En el caso del personaje de Sirena, el acto travesti (indisociable de su performance como cantante) se convierte, paradójicamente, en un mecanismo de supervivencia dentro de un mundo patriarcal que lo condena al ostracismo y lo oprime bajo su violencia física y emocional (...) [Por consiguiente,] el joven utiliza su propia apariencia como sujeto sexualmente indefinible y/o ambiguo, según los códigos normativos de identificación, y lo radicaliza a través de su acto travesti, el cual maravilla a los espectadores, precisamente, por el misterio de la seducción que su cuerpo ejerce. (PEÑA-JORDÁN, 2005, p. 275)

Para Peña-Jordán, a travestilidade em Sirena não aparece como uma necessidade identitária, como no caso de Martha Divine, mas como uma prática que permite sua subversão e acesso a uma esfera social que antes lhe era negada. Logo, a personagem incorpora características femininas e se vale de seus traços delicados, que antes a condenavam, para performar a cantora Sirena Selena. A partir de sua personagem, joga com os desejos socialmente proibidos da classe dominante, "revelando en el proceso el revés de las estruturas en las que se cose el tejido nacional heterosexista" (PEÑA-JORDÁN, 2005, p. 275) seduzindo-os até o ponto de os controlar.

Além da voz, a travestilidade como proteção de Sirena explica o fato da personagem abandonar Hugo Graubel no final da trama. Isso porque, junto a ele, Sirena sentia-se despregada de seu corpo, não apenas porque na obra o sentimento amoroso é construído como aquele que causa vulnerabilidade e transparência, não podendo coexistir com o disfarce; mas também pelo 
fato de que, conforme construíam uma relação íntima, o empresário começa a identificá-la como "Sirenito", desapropriando-a de sua performance feminina. Logo, Sirena se sente desprotegida e o abandona:

Ese Cliente le había trastocado las pautas de su acostumbrado plan, y a ella cada vez se la hacía más difícil mantenerse envuelta en la ilusión de amor y entrega que hasta ahora la había protegido. Algo en Hugo la hacía vulnerable a la realidad. [...] No, eso no podía ser. Ella no podía permitirse depender de este anfitrión. No debía confiar de la mano que tira sobras a perros callejeros. (SANTOS-FEBRES, 2011, p. 241, 244)

Desse modo, fugir da armadilha de Hugo e dos sentimentos que ele suscitava, significa não só se manter na pele de sereia que a protegia, mas também, não depender economicamente e sentimentalmente de um empresário que, dentro da lógica colonial, se apropriava das riquezas e dos corpos caribenhos para enriquecer.

Além da questão da performatividade de gênero e da constituição de corpos nãonormativos, o trânsito das personagens entre as ilhas e as especificidades de cada uma apontam para as questões do Caribe como um todo. A narrativa evidencia não uma escritora boricua tratando das problemáticas de Porto Rico, mas um tom panantillanista ${ }^{5}$. O panatillanismo, ou antillanismo, segundo Emilio Cordero Michel (2010), é desenvolvido pela primeira vez no "Seminario Internacional Martí, Gómez y el antillanismo", de 1860, instituindo-se como uma corrente ideológica que surge no início da segunda metade do século XIX, como uma aliança fraternal entre Cuba e República Dominicana. Suas primeiras diretrizes eram antiescravistas e contra a dominação espanhola. Hoje, o panorama antilhano busca uma união entre as ilhas com reivindicações políticas e sociais de caráter independentista, antianexionista e anti-imperialista.

Com a viagem das portorriquenhas Martha Divine e Sirena à República Dominicana, a obra de Santos-Febres apresenta as problemáticas econômicas e sociais comuns a esses países, posto que ambos dependem do turismo e se enriquecem com a venda de corpos caribenhos a turistas e ricos empresários. Da mesma forma, Cuba também aparece no romance como lugar

\footnotetext{
${ }^{5} \mathrm{O}$ panantillanismo na obra é proposto tanto por Efraín Barradas, em "Sirena Selena vestida de pena o el Caribe como travestí", quanto por Teresa Peña-Jordán, no capítulo "El travestismo como estrategia de supervivencia en el Caribe: una lectura de Sirena Selena vestida de pena de Mayra Santos-Febres” de seu livro.
} 
de repressão aos corpos que não estão inseridos na lógica normativa dos papéis de gênero, com a presença da personagem de uma draga, amiga de Martha Divine ${ }^{6}$.

Além do espaço da narrativa que transita de Porto Rico à República Dominicana, há uma relação de espelhamento entre as personagens que intensificam essa relação transnacional. Isso ocorre principalmente com Sirenito (boricua) e Leocádio (dominicano). Essas personagens apresentam um passado similar em relação à ausência paterna, à morte da mãe de Leocadio e da avó de Sirenito e o desamparo que sofrem; além disso, são identificados como corpos frágeis, andróginos, negros e pobres. Tal identificação parte deles mesmos, gerando uma relação de cumplicidade diante da imagem do outro, simbolizada, no fragmento que segue, pelo sorriso de ambos, quando Leocadio vê Sirena(o) na praia:

Leocadio caminó hacia aquella aparición y la miró con una curiosidad que no podía disimular. Era un muchacho, un muchacho que parecía una nena, igual que él, igual que su hermana, pero con la piel color canela clara, el pelo muy oscuro y las cejas depiladas. El muchacho le devolvió la mirada con un hastío hostil. Pero, después, el chico le regaló una sonrisa. Leocadio también sonrió (SANTOS-FEBRES, 2011, p. 57).

Em suma, a subversão dos estereótipos degênero e a denúncia política, juntas, constituem o eixo principal do romance Sirena Selena vestida de pena, que além de atribuir o protagonismo da narrativa a personagens que fogem das regras binárias e disciplinares de uma sociedade patriarcal, cis-sexista e heterossexista, denuncia as problemáticas socioeconômicas do Caribe. Portanto, a travestilidade não apenas estabelece uma denúncia política da dependência dos países caribenhos do turismo sexual e da exploração econômica por parte de empresários e turistas, mas aparece como uma ferramenta de resistência e possibilidade de sobrevivência.

Mayra Santos-Febres, além da denúncia, transmite a seus leitores a possibilidade de um futuro distinto da realidade apresentada pela trama: uma realidade em que a violência contra os corpos não normativos e a exploração econômica dos países caribenhos não existam mais. Frente a isso é importante ressaltar dois momentos da narrativa, o primeiro seria a cena vista por Martha na qual Leocádio e Migueles dançam no salão do hotel. Neste momento, há a

\footnotetext{
${ }^{6}$ A personagem apresentada por Martha Divine, cujo nome a empresária não se lembra, é vítima da violência que sofre na rua (SANTOS-FEBRES, p. 36).

Jangada | nr. 9, jan/jun, 2017 | ISSN 2317-4722 - 31 | Pá g in a
} 
representação de dois corpos rechaçados econômica e racialmente disfrutando de um lugar que lhes era antes privado. Igualmente, a demonstração pública e afetiva, que Martha reconhece como uma relação homossexual, representaria a dissolução dos valores heteronormativos da sociedade:

Sin embargo, había un área prohibida para Leocadio: la barra del hotel. Esa área estaba fuera de límites para todos los muchachos que trabajaban moviendo cajas, cortando vegetales o limpiando cuartos de huéspedes. El mundo de la barra era exclusivo de los meseros. [...] Migueles tomó a Leocadio de la mano, le pasó el otro brazo por la cintura y lo pegó contra él mientras sonreía. Al principio, Leocadio se sintió incómodo en los brazos de su amigo. Pero sabía que, si Migueles lo notaba, terminaria su visita al bar. Para ocultar su turbación, Leocadio puso cara de señorita tímida, batió pestañas y bailó con Migueles en aquella pista llena de brillo y de lucecitas que prendían y apagaban. Después, se distrajo un poco, mirando los reflejos de las luces sobre los cristales de las paredes. El piso entero estaba cubierto por reflejos de luciérnagas bailarinas que los envolvían a los dos. Migueles seguía bailando um ritmo íntimo. Leocadio trataba de tragárselo todo con los ojos. El sistema de sonido permanecía apagado, pero él juraba que oía música sonar. Música bailable extranjera, de esa que, a veces, llegaba a oírse abajo en el recibidor. Migueles guiaba los pasos, y Leocadio puso atención en aprenderse el son que dirigía el baile. Miró a su amigo con los ojos brillosos de alegría. (SANTOS-FEBRES, 2011, pp. 228, 259)

Por fim, outro momento de grande importância é o discurso final de Martha Divine, em que afirma:

Hay que mantenerse positivas. Aunque una se sienta como un trapo usado por que la vida le pudre el pecho como una llaga mala. Aunque los policías las corran a la salida de la disco por mariconas y el marido se les vaya con otra. Aunque vivan en un cuartito lleno de cucarachas y la polilla les coma los trajes que con tantas privaciones se han cosido, para gozarse un instante de lujo en esta barra de mala muerte. Aunque una, de tanto cantazo, ya no sepa reconocer el amor. Ustedes sigan esperando su buena estrella. Ella está allá arriba, brillando en el firmamento, augurándoles un futuro de lujo y felicidad [...] La mía casi la veo a la punta de mis manos. Siento que la alcanzo. Les juro que 


\section{jangada}

hay días en que creo que con la punta de los dedos la puedo tocar. (SANTOSFEBRES, 2011, p. 272)

Tal fala encerra o romance com um tom de confiança e esperança na transformação desta sociedade violenta, que oprime constantemente corpos como o de Martha: caribenhos e não normativos.

\section{REFERÊNCIAS BIBLIOGRÁFICAS}

BARRADAS, Efraín. Sirena Selena Vestida de Pena o el Caribe como travestí. In: SandovalSánchez. A Queer Dossier: Mayra Santos-Febres 'Sirena Selena vestida de Pena, New York: Centro Journal, 2003, pp.52-65.

BRAIDOTTI, Rosi. Metamorphoses: towards a Materialist Theory of Becoming. Cambridge: Polity Press, 2002.

BUTLER, Judith. Problemas de gênero: feminismo e subversão da identidade. $8^{\mathrm{a}}$ ed., Tradução Renato Aguiar. Rio de Janeiro: Civilização Brasileira, 2015.

CORDERO Michel, Emilio. Máximo Gómez y el antillanismo. In: Clio: Santo Domingo, 2010. Disponível em:

http://clio.academiahistoria.org.do/trabajos/clio179/Clio_2010_No_179-06.pdf

DÍAZ, Luis Felipe. La narrativa de Mayra Santos y el travestismo cultural. In: SandovalSánchez, A Queer Dossier: Mayra Santos-Febres 'Sirena Selena vestida de Pena'. Centro: Journal of the Center for Puerto Rican Studies 15:2, 2003 p.24-37.

FOUCAULT, Michel. Microfísica do poder. Rio de Janeiro: Graal, 1979.

KEMPADOO, Kamala. Sexing the Caribbean: gender, race and sexual labor. New York: Routledge, 2004.

LIPSCHUTZ, Alejandro. El problema racial de la conquista de América. México: Siglo XXI, 1975.

LÓPEZ Guevara, Alejandra. Travestismo y humor en Sirena Selena vestida de pena, de Mayra Santos-Febres. Apuntes desde el carnaval bajtiniano. In: Anuario de Letras Hispánicas. Glosas hispánicas, 2011, Volumen 2. Universidad Nacional Autónoma de México. Facultad de Filosofía y Letras, México 2013. Disponível em: http://ru.ffyl.unam.mx:8080/jspui/bitstream/10391/3807/1/07_ALH_2011_Lopez_101-

\section{1.pdf}

PEÑA-Jordan, Teresa, El travestismo como estrategia de supervivencia en el Caribe: una lectura de Sirena Selena vestida de pena de Mayra Santos-Febres. In: Cuerpo político del deseo: literatura, género e imaginário geocultural en Cuba y Puerto Rico. University of Pittsburgh, 2005. p. 274-312.

SANTOS-Febres, Mayra. Sirena Selena Vestida de Pena. Barcelona: Mondadori, 2000. 